\title{
Article \\ Bacillus velezensis Strains for Protecting Cucumber Plants from Root-Knot Nematode Meloidogyne incognita in a Greenhouse
}

\author{
Anzhela M. Asaturova 1, Ludmila N. Bugaeva ${ }^{2}$, Anna I. Homyak 1,*(D), Galina A. Slobodyanyuk ${ }^{2}$, \\ Evgeninya V. Kashutina ${ }^{2}$, Larisa V. Yasyuk ${ }^{2}$, Nikita M. Sidorov ${ }^{1}$, Vladimir D. Nadykta ${ }^{1}$ \\ and Alexey V. Garkovenko ${ }^{3,4}$ (D)
}

check for updates

Citation: Asaturova, A.M.; Bugaeva, L.N.; Homyak, A.I.; Slobodyanyuk, G.A.; Kashutina, E.V.; Yasyuk, L.V.; Sidorov, N.M.; Nadykta, V.D.; Garkovenko, A.V. Bacillus velezensis Strains for Protecting Cucumber Plants from Root-Knot Nematode Meloidogyne incognita in a Greenhouse. Plants 2022, 11, 275. https://doi.org/10.3390/plants 11030275

Academic Editors:

Carlos Agustí-Brisach and

Eugenio Llorens

Received: 29 December 2021

Accepted: 17 January 2022

Published: 20 January 2022

Publisher's Note: MDPI stays neutral with regard to jurisdictional claims in published maps and institutional affiliations.

Copyright: (C) 2022 by the authors. Licensee MDPI, Basel, Switzerland. This article is an open access article distributed under the terms and conditions of the Creative Commons Attribution (CC BY) license (https:// creativecommons.org/licenses/by/ $4.0 /)$.
1 Federal Research Center of Biological Plant Protection, p/o 39, 350039 Krasnodar, Russia; biocontrol-vniibzr@yandex.ru (A.M.A.); elisitor@mail.ru (N.M.S.); vnadykta@mail.ru (V.D.N.)

2 Lazarevskaya Experimental Plant Protection Station, the Affiliated Branch of the Federal Research Centre of Biological Plant Protection, 1. 200, Sochi Highway-77, 354200 Sochi, Russia; bugaevaln@mail.ru (L.N.B.); bugaeval@mail.ru (G.A.S.); kashutinaev@mail.ru (E.V.K.); gnu_oszr@mail.ru (L.V.Y.)

3 Shemyakin-Ovchinnikov Institute of Bioorganic Chemistry of the Russian Academy of Sciences, Miklukho-Maklaya Str. 16/10, 117997 Moscow, Russia; garkovenko@gmail.com

4 Laboratory of Molecular Genetic Research in the Agroindustrial Complex, Department of Biotechnology, Biochemistry and Biophysics, Trubilin Kuban State Agrarian University, Kalinina Str. 13, 350044 Krasnodar, Russia

* Correspondence: HomyakAI87@mail.ru; Tel.: +7-(967)-311-58-10

\begin{abstract}
Meloidogyne incognita Kofoid et White is one of the most dangerous root-knot nematodes in greenhouses. In this study, we evaluated two Bacillus strains (Bacillus velezensis BZR 86 and Bacillus velezensis BZR 277) as promising microbiological agents for protecting cucumber plants from the root-knot nematode $M$. incognita Kof. The morphological and cultural characteristics and enzymatic activity of the strains have been studied and the optimal conditions for its cultivation have been developed. We have shown the nematicidal activity of these strains against $M$. incognita. Experiments with the cucumber variety Courage were conducted under greenhouse conditions in 2016-2018. We determined the effect of plant damage with $M$. incognita to plants on the biometric parameters of underground and aboveground parts of cucumber plants, as well as on the gall formation index and yield. It was found that the treatment of plants with Bacillus strains contributed to an increase in the height of cucumber plants by $7.4-43.1 \%$, an increase in leaf area by $2.7-17.8 \%$, and an increase in root mass by 3.2-16.1\% compared with the control plants without treatment. The application of these strains was proved to contribute to an increase in yield by $4.6-45.8 \%$ compared to control. Our experiments suggest that the treatment of cucumber plants with two Bacillus strains improved plant health and crop productivity in the greenhouse. B. velezensis BZR 86 and B. velezensis BZR 277 may form the basis for bionematicides to protect cucumber plants from the root-knot nematode $M$. incognita.
\end{abstract}

Keywords: B. velezensis; cultivation conditions; cucumber; root-knot nematode; Meloidogyne incognita; greenhouse

\section{Introduction}

In greenhouses, the diversity of harmful species is less than in the field, however, the specific microclimate in greenhouses, as well as the absence of natural enemies as regulatory factors, lead to pest accumulation and increase its harmfulness to cultivated plants. Parasitic phytonematodes are among the most serious pests that negatively affect the quality of vegetables in a greenhouse [1,2]. They are obligate parasites that feed mostly on plant roots with common aboveground symptoms of stunting, yellowing, wilting, and yield losses and belowground root malformation due to direct feeding damage. These factors lead to yield losses [3]. Parasitic phytonematodes feed on many crops worldwide and they can cause enormous yield losses with an estimation of 100 billion dollars a year [4]. 
Root-knot nematodes are one of the most harmful groups of phytophagous organisms in greenhouses. About $5 \%$ of world crop production is annually destroyed by Meloidogyne spp. Gall nematodes induce overgrowth of root cells, which leads to the formation of galls on plant roots. The nematode damages the vascular tissue of the roots, thereby interfering with the normal movement of water and nutrients. Infected plants show signs of nutrient deficiency: slow growth, yellowing of leaves, wilting, and dying off of the plant. In such a condition, the yield of plants can drop by $50-80 \%$, and in some cases, there is an entire yield loss [5]. Control of nematodes in greenhouses is expensive and time-consuming, and none of the existing methods completely relieves the plant from its presence. To reduce the number of nematodes in greenhouses, agricultural producers use resistant varieties and steam the soil. In addition, soil fumigation with highly toxic substances prohibited in greenhouses is often used. [6].

In recent years, there have been numerous studies worldwide concerning the possibility of reducing the harmfulness of phytopathogenic nematodes using antagonistic microorganisms [7-9]. Active strains of antagonistic bacteria with high nematicidal activity in combination with high biological and economic efficiency have been identified. Special attention of the experts is paid to Bacillus, Pseudomonas, and Pasteuria bacterial strains [10-13]. In addition, many researchers have found the nematicidal activity of the metabolites of Trichoderma, Paecilomyces, Arthrobotrys, Beauveria, Pochonia, Fusarium, and Myrothecium fungi [14-16].

Currently, successful research has been carried out and technologies have been developed for the development of biological products, such as Bioact WG (Purpureocillium lilacinus), KlamiC (Pochonia chlamydosporia), Econem (Pasteuria penetrans), Deny, Blue Circle (Burkholderia cepacia), DiTera (Myrothecium Verruotia), and Nortica VOTiVO (Bacillus firmus). Giant corporations, such as BASF and Bayer CropScience, which are key suppliers of plant protection products in the world market, became interested in the production of these preparations. It should be noted that some products are produced only for use in the country of manufacture [17]. However, none of these biological products are registered for use in Russia.

Currently, only one formulation, Phytoverm, based on Streptomyces avermectilis metabolites, is registered against phytonematodes in Russia. However, this group of products belongs to the category of agrochemicals and is prohibited for use in organic farming technologies. So far, there is no registered biological product based on microorganisms against phytonematodes in Russia [18]. The reasons for such a poor assortment of biological products are the insufficient knowledge of the biological characteristics of bacterial and fungal strains as the basis of nematicidal biological products, as well as the study of their trophic needs and resistance to various factors.

Thus, one of the promising solutions to the problem of protecting plants from $M$. incognita can be biological control of the pest population based on the use of effective microbiological agents that are currently not available in Russia.

This study focused on the isolation, identification, and characterization of $B$. velezensis BZR 86 and B. velezensis BZR 277 isolated from winter wheat roots. They showed high fungicidal activity against F. graminearum [19] and high nematicidal activity in vitro against the root-knot nematode $M$. incognita Kofoid et White [20]. The strains were selected from the BRC «State collection of beneficial insects, mites and microorganisms» of the Laboratory for the creation of microbiological plant protection products and the collection of microorganisms (FSBSI FRCBPP, Russia), since they have enzymatic, growth-stimulating, and nematicidal activity against the root-knot nematode $M$. incognita. In addition, the conditions for cultivating Bacillus strains were optimized.

\section{Results}

\subsection{Characteristics and Identification of Bacillus strains}

The cells of the $B$. velezensis BZR 86 strain are rod-shaped with rounded ends; single or paired; cells are motile; and have sizes of 2.8-4.1 × 6.6-9.4 microns. The cells usually contain 
spores. Coloring indicates positive results in the Gram stain. On the MPA, the shape of the colonies is round with a scalloped edge. The colonies are shiny and colorless. The profile of the colonies is flat, the edge is wavy, the structure is fine-grained, the texture is soft, and the colonies do not stick to the loop. The diameter of the colonies is $2-4 \mathrm{~mm}$. On the PGA, rhizoid colonies with a smooth edge are formed. The colonies are matte and cream-colored. The profile of the colonies is convex, the structure is streaky in the center, fine-grained along the edge, the texture is soft, mucous, and the colonies adhere to the loop. The diameter of the colonies is $1-3 \mathrm{~mm}$.

B. velezensis BZR 277 cells are rod-shaped with rounded ends; single or paired; cells are motile; and have sizes of 1.3-1.8 $\times$ 4.5-5.4 microns. The cells usually contain spores. Coloring indicates positive results in the Gram stain. On the MPA, the shape of the colonies is round with a scalloped edge. Colonies are opaque and colorless. The profile of the colonies is flat, the structure is fine-grained, the texture is soft, and the mucous colonies adhere to the loop. The diameter of the colonies is $0.5-2 \mathrm{~mm}$. On the PGA, rhizoid colonies with a smooth edge are formed. Colonies are matte and cream-colored or yellowish-brown. The profile of the colonies is curved, the structure is streaky, the consistency is soft, mucous, and the colonies adhere to the loop. The diameter of the colonies is $1-3 \mathrm{~mm}$.

MALDI-TOF MS analysis of bacterial colonies of the studied strains showed score values of $\geq 0.65$ (BactoSCREEN ID) and $\geq 1.952$ (Bruker Autoflex). These data confirm taxonomic identification only up to the genus Bacillus (Figure 1).

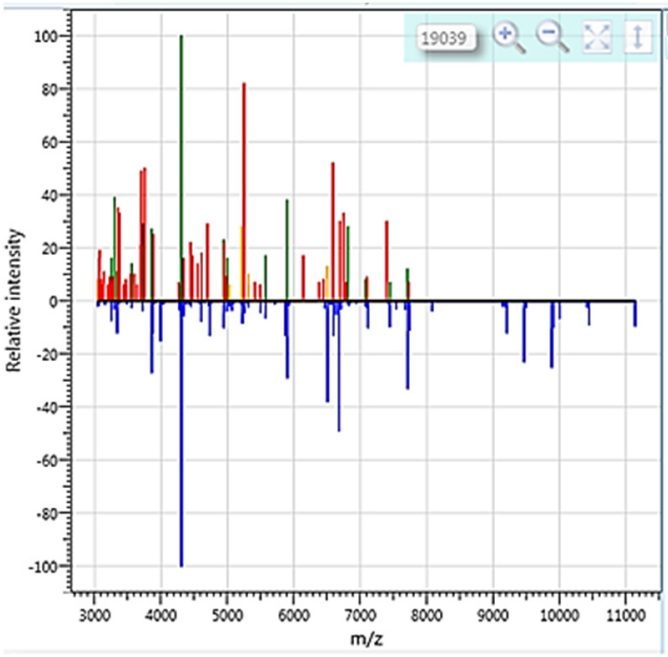

(A)

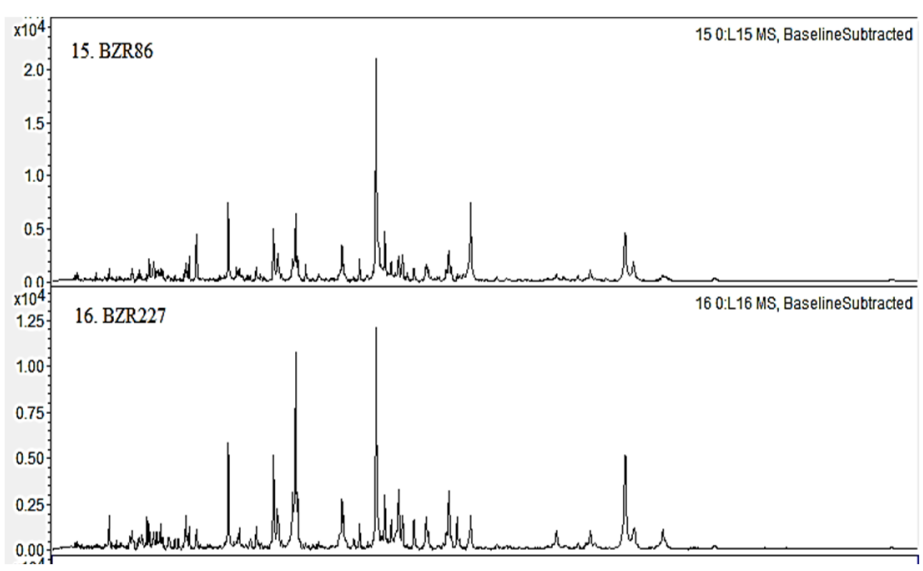

(B)

Figure 1. Identification of Bacillus strains BZR 86 and BZR 277: (A) Unique spectrum of ribosomal proteins of strain BZR 86 (blue peaks belong to the reference strain Bacillus subtilis, the rest of the peaks in the upper part of the profile belong to the studied strain BZR 86 (BactoSCREEN)). Green and yellow peaks coincide with the data of the reference strain B. subtilis, red ones do not match. Similar data were obtained by this method for the BZR 277 strain (data not shown); (B) Unique ribosomal protein spectra of strains BZR 86 and BZR 277 showing taxonomic identity of strains (Bruker).

A phylogenetic tree based on genome-wide sequencing of 120 conserved marker genes shows that strains BZR 86 and BZR 277 clearly cluster with B. velezensis NRRL B-41580 (B. velezensis GCF 001461825.1 at the phylogenetic level); the average nucleotide identity (ANI) is $97.59 \%$ (Figure 2). Strains BZR 86 and BZR 277 are closer to B. siamensis and B. amyloliquefaciens than to B. subtilis (as determined using $16 \mathrm{~S}$ rRNA). 


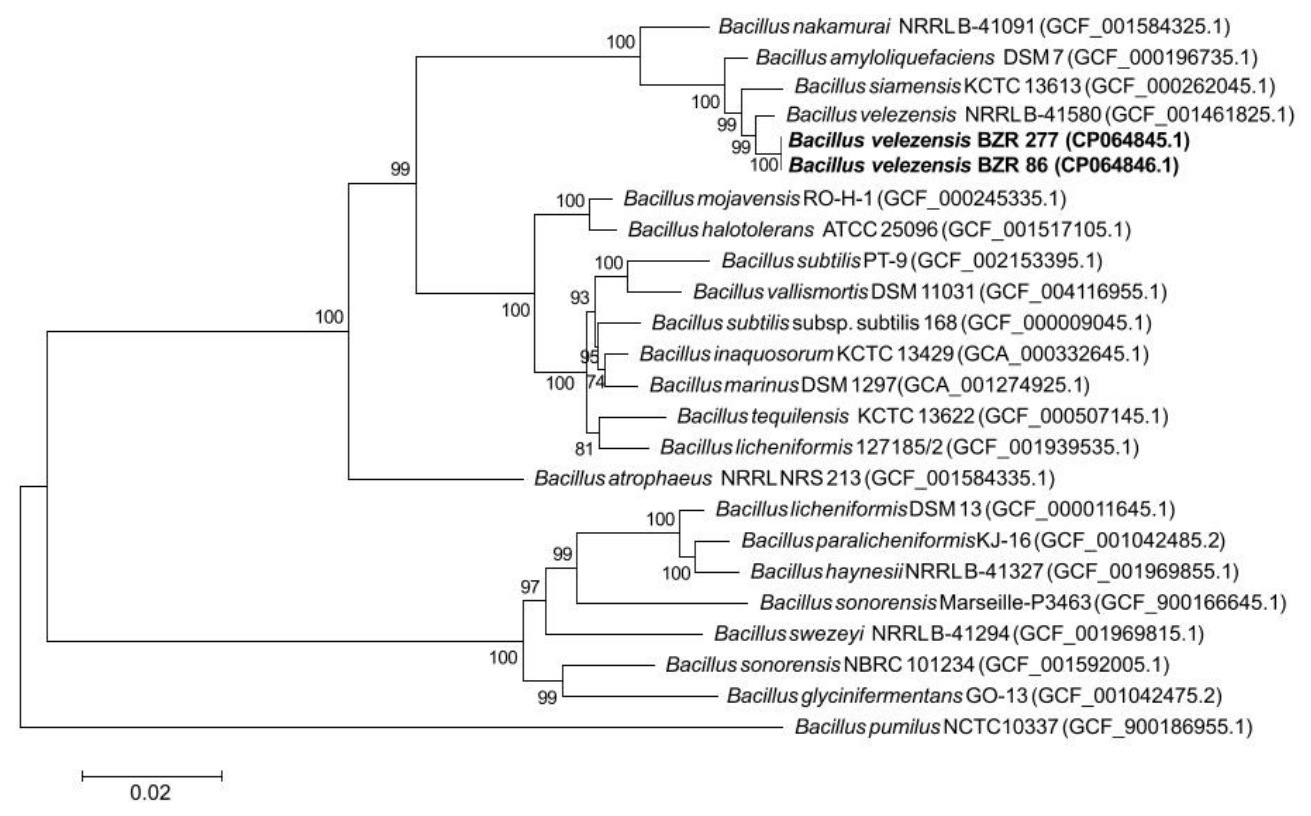

Figure 2. Maximum likelihood phylogenetic tree constructed using amino acid sequences of 120 conserved marker genes. The tree was constructed using PhyML v.3.3.

\subsection{Enzymatic Activity of B. velezensis BZR 86 and B. velezensis BZR 277 Strains}

It is known that effective lysis of the cell walls of pests is associated with the complex action of various hydrolytic enzymes. Therefore, the ability of Bacillus strains to produce various hydrolytic enzymes was studied. We revealed a different level of synthesis of lytic enzymes in the bacterial strains (Table 1).

Table 1. Enzymatic activity of B. velezensis BZR 86 and B. velezensis BZR 277 strains.

\begin{tabular}{ccccc}
\hline \multirow{2}{*}{ Strain } & \multicolumn{4}{c}{ Enzymatic Activity } \\
\cline { 2 - 5 } & Lipase & Chitinase & Protease & Gelatinase \\
\hline B. velezensis BZR 86 & - & + & - & + \\
\hline B. velezensis BZR 277 & +++ & - & +++ & + \\
\hline - no activity; + low activity; ++ mean activity; +++ high activity.
\end{tabular}

The B. velezensis BZR 277 strain showed the ability to synthesize protease and lipolytic enzymes, while $B$. velezensis BZR 86 strain showed the ability to synthesize chitinases only. Both strains produce gelatinase. When inoculating with a prick on a gelatinous medium in a test tube, it was noted that the $B$. velezensis BZR 86 strain forms a crater-like liquefaction of the gelatinase medium, and the B. velezensis BZR 277 strain forms a turnip-like one.

\subsection{Cultivation Conditions for B. velezensis BZR 86 and B. velezensis BZR 277 Strains}

In our studies, five parameters were identified that affect the growth of strains in the process of periodic cultivation: cultivation temperature, the acidity of the medium, sources of carbon and nitrogen nutrition, and cultivation time. During the study, we found that some parameters, such as temperature and acidity of the environment, have a significant effect on cell growth. When the incubation temperature changed from 20 to $35^{\circ} \mathrm{C}$, and the acidity of the medium from 3 to 10 , there was significant variation in the titer (Table 2). 
Table 2. The number of colony-forming units in liquid cultures is based on strains B. velezensis BZR 86 and B. velezensis BZR 277, depending on the cultivation conditions.

\begin{tabular}{|c|c|c|}
\hline \multirow{2}{*}{ Parameter } & \multicolumn{2}{|c|}{ Titer, CFU/ml } \\
\hline & B. velezensis BZR 86 & B. velezensis BZR 277 \\
\hline & Temperature, ${ }^{\circ} \mathrm{C}$ & \\
\hline 20.0 & $(9.6 \pm 0.14)^{1} \times 10^{6} b^{2}$ & $(3.4 \pm 0.3) \times 10^{5} \mathrm{~b}$ \\
\hline 25.0 & $(8.6 \pm 0.42) \times 10^{6} a$ & $(6.2 \pm 0.14) \times 10^{5} \mathrm{a}$ \\
\hline 30.0 & $(8.3 \pm 0.67) \times 10^{6} \mathrm{a}$ & $(1.4 \pm 0.04) \times 10^{6} \mathrm{c}$ \\
\hline 35.0 & $(1 \pm 0.05) \times 10^{7} \mathrm{c}$ & $(6.6 \pm 0.17) \times 10^{5} \mathrm{a}$ \\
\hline & $\mathrm{pH}$ & \\
\hline 3.0 & $(3.2 \pm 0.06) \times 10^{7} \mathrm{c}$ & $(4.3 \pm 0.2) \times 10^{6} \mathrm{~d}$ \\
\hline 6.0 & $(7.6 \pm 0.3) \times 10^{6} a$ & $(1.7 \pm 0.3) \times 10^{6} \mathrm{c}$ \\
\hline 8.0 & $(1.1 \pm 0.14) \times 10^{7} \mathrm{~b}$ & $(1.2 \pm 0.02) \times 10^{6} \mathrm{~b}$ \\
\hline 10.0 & $(1.1 \pm 0.4) \times 10^{7} \mathrm{~b}$ & $(1.1 \pm 0.05) \times 10^{6} \mathrm{a}$ \\
\hline & Carbon sources & \\
\hline sucrose & $(2.3 \pm 0.36) \times 10^{6} a$ & $(6.2 \pm 0.6) \times 10^{5} \mathrm{a}$ \\
\hline glucose & $(3.1 \pm 0.22) \times 10^{6} a$ & $(6.6 \pm 0.75) \times 10^{5} \mathrm{a}$ \\
\hline glycerol & $(2.3 \pm 0.25) \times 10^{6} a$ & $(1 \pm 0.02) \times 10^{6} a$ \\
\hline molasses & $(1.6 \pm 0.03) \times 10^{9} \mathrm{~b}$ & $(5.8 \pm 0.39) \times 10^{8} \mathrm{~b}$ \\
\hline & Nitrogen sources & \\
\hline NaNO3 & $(3.7 \pm 0.4) \times 10^{6} \mathrm{a}$ & $(7 \pm 0.66) \times 10^{7} \mathrm{a}$ \\
\hline peptone & $(1.8 \pm 0.07) \times 10^{8} \mathrm{e}$ & $(4.7 \pm 0.4) \times 10^{8} \mathrm{c}$ \\
\hline yeast extracts & $(4 \pm 0.2) \times 10^{7} \mathrm{~b}$ & $(5.2 \pm 0.5) \times 10^{7} \mathrm{a}$ \\
\hline corn extracts & $(9.4 \pm 0.3) \times 10^{7} \mathrm{c}$ & $(1.1 \pm 0.05) \times 10^{8} \mathrm{~b}$ \\
\hline & Cultivation time, $\mathrm{h}$ & \\
\hline 8 & $(2.5 \pm 0.15) \times 10^{6} a$ & $(1.2 \pm 0.05) \times 10^{7} \mathrm{a}$ \\
\hline 16 & $(7.4 \pm 0.37) \times 10^{8} \mathrm{~b}$ & $(4.7 \pm 0.35) \times 10^{8} \mathrm{~b}$ \\
\hline 24 & $(1.3 \pm 0.11) \times 10^{9} \mathrm{~d}$ & $(1.7 \pm 0.02) \times 10^{9} \mathrm{~d}$ \\
\hline 36 & $(1.2 \pm 0.06) \times 10^{9} \mathrm{c}$ & $(1.6 \pm 0.04) \times 10^{9} \mathrm{c}$ \\
\hline 48 & $(2.3 \pm 0.35) \times 10^{7} \mathrm{a}$ & $(4 \pm 0.02) \times 10^{7} \mathrm{a}$ \\
\hline 72 & $(1.1 \pm 0.2) \times 10^{7} \mathrm{a}$ & $(9.4 \pm 0.3) \times 10^{7} \mathrm{a}$ \\
\hline
\end{tabular}

${ }^{1}$ The error corresponds to the standard deviation of three independent analyses. ${ }^{2}$ Between the options marked with the same letters, when comparing within the columns there are no statistically significant differences according to the Duncan criterion at a 95\% probability level-\% increase to control. Each optimal parameter is determined while keeping the other parameters unchanged.

A high spore or cell titer for the B. velezensis BZR 86 strain was noted at a temperature of $35^{\circ} \mathrm{C}$ and for the B. velezensis BZR 277 strain at a temperature of $30^{\circ} \mathrm{C}$. The optimal $\mathrm{pH}$ for both strains was three. Different nutrient sources had a more significant effect on cell growth. Thus, molasses had appeared to be the optimal carbon source for both strains. The highest titer was recorded on a nutrient medium, where peptone was used as a nitrogen source. The maximum cell titer for both strains was noted in the range of $24-36 \mathrm{~h}$ of cultivation. When studying the influence of the cultivation time on the dynamics of the growth of the strains, it was noted that the phase of initial growth (the period when the volume of cells increased, but not their number) began after the introduction of the parent culture into the medium and lasted up to $8 \mathrm{~h}$. The phase of the most active growth began $16 \mathrm{~h}$ after the introduction of the parent culture and reached its maximum in 24-36 h for both strains. This was followed by a phase of withering away.

\subsection{Study of B. velezensis BZR 86 and B. velezensis BZR 277 Strains under Greenhouse Conditions}

As a result of comprehensive monitoring, it was found that the cause of the formation of the galls on plant roots is the root-knot nematode M. incognita. In 2016-2018, B. velezensis BZR 277 and B. velezensis BZR 86 strains were tested against the M. incognita on cucumber plants in the greenhouse. In 2016, a single soil treatment under the root during planting with the studied strains led to plant growth retardation, shredding, and necrosis of the leaves, 
and then plants wilting. The double treatment under the root with Bacillus strains during the entire growing season caused intensive plant development and no visual signs of plant damage by the nematode were observed. Growth and development indicators of plants after treatment with Bacillus strains significantly exceeded the control. The vegetative period of plants lasted for three months. To the end of the period, complete drying of the control plants was noted. Phytopathological analysis of cucumber plant samples showed that no signs of damage by peronosporosis and powdery mildew were discovered on the plants (Figure 3).

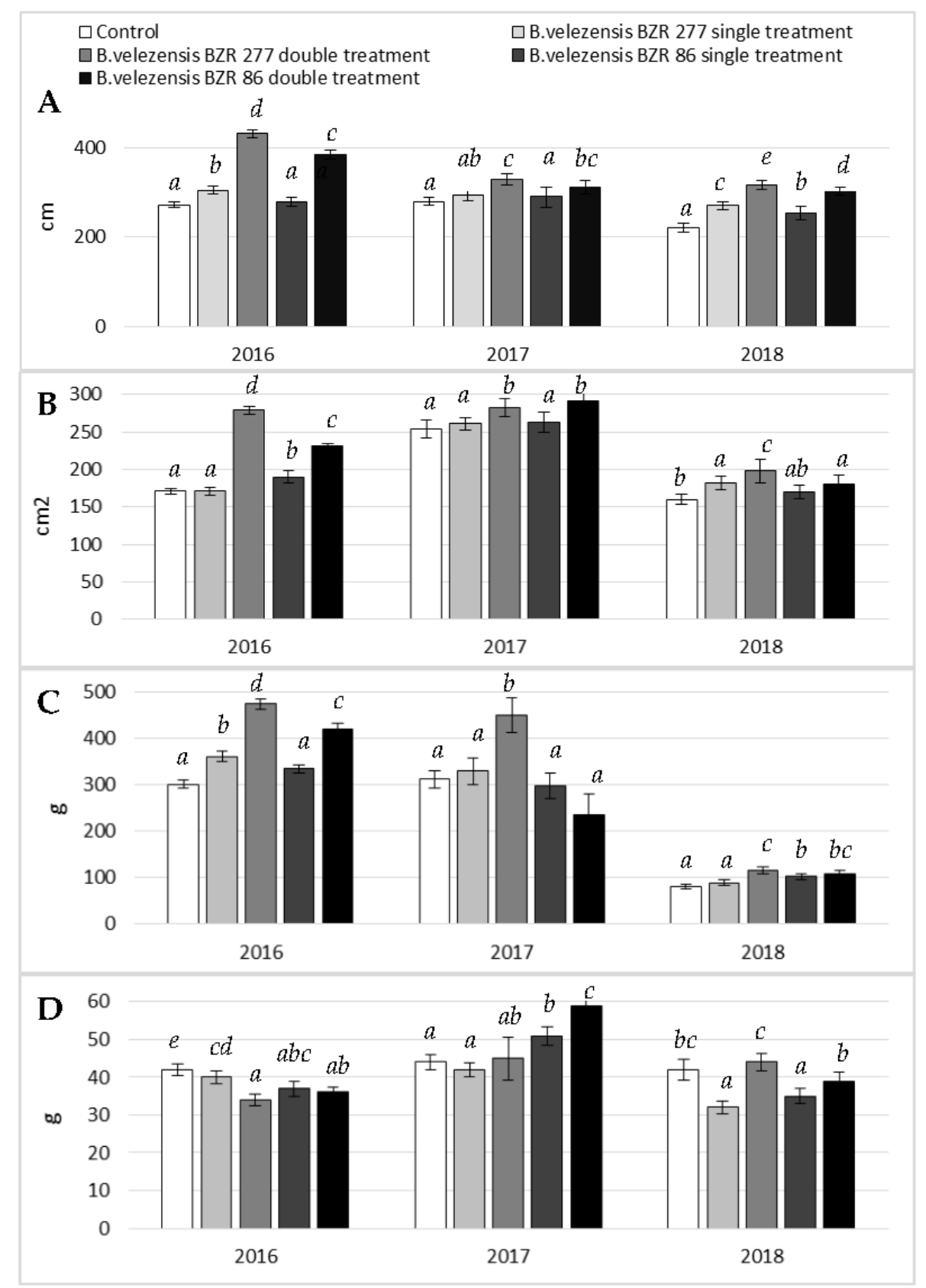

Figure 3. Effect of B. velezensis BZR 86 and B. velezensis BZR 277 treatment on the growth and development of cucumber plants in the greenhouse, 2016-2018: (A) plant height, cm; (B) leaf area, $\mathrm{cm}^{2}$; (C) shoot mass, $\mathrm{g}$; (D) root mass, $\mathrm{g}$. The results are presented as the mean \pm standard deviation. Different letters in each column indicate significant difference $(\mathrm{p} \leq 0.05)$. 
In 2016, the gall index for the B. velezensis BZR 86 strain was five times less, and for the B. velezensis BZR 277 strain was 14 times less, than in the control. However, yield is provided not only by a decrease in the number of galls, but also by a direct effect on the growth and development of plants. Therefore, the yield of cucumber plants treated with the studied strains was 5.2\% higher for B. velezensis BZR 277 (a double treatment), and 21.4\% higher for B. velezensis BZR 86 (a double treatment) compared to the control (Figure 4).

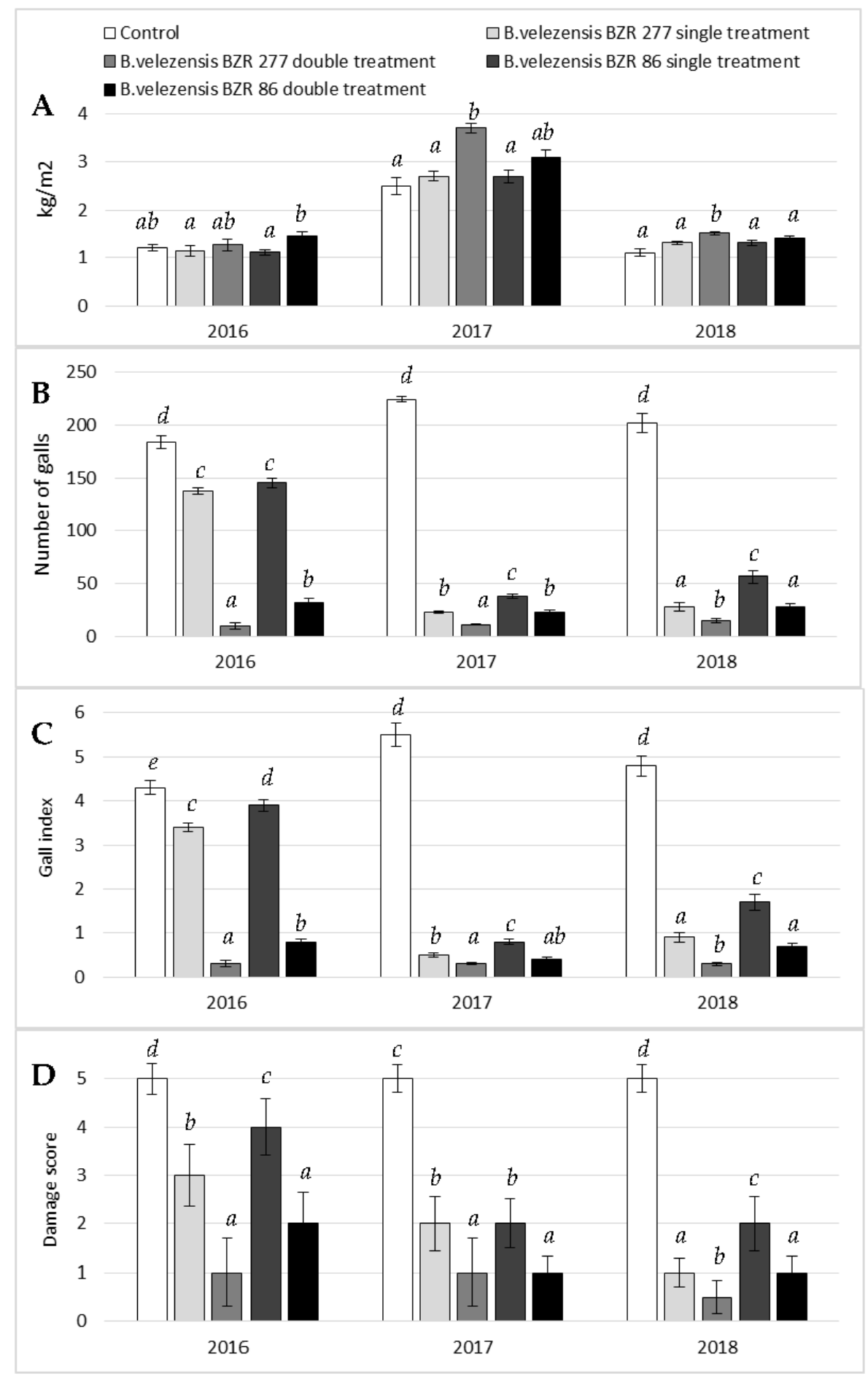

Figure 4. Effect of B. velezensis BZR 86 and B. velezensis BZR 277 treatment on cucumber yield and gall index in a greenhouse, 2016-2018: (A) yield, $\mathrm{kg} / \mathrm{m}^{2} ;$ (B) number of galls; (C) gall index; (D) damage score. The results are presented as the mean \pm standard deviation. Different letters in each column indicate significant difference $(p \leq 0.05)$. 
In 2017, a double treatment of cucumber plants with B. velezensis BZR 86 and B. velezensis BZR 277 strains was statistically more effective than a single treatment. It was noted that the $B$. velezensis BZR 277 strain had a greater effect on the development of the aerial part of cucumber plants, while the B. velezensis BZR 86 strain stimulated the development of the root system (Figures 3 and 5). Due to the increase in the underground part, a higher percentage of nematode damage was noted for B. velezensis BZR 86 strain: two times compared to B. velezensis BZR 277. Both strains were noted to influence an increase in yield by $17.8-45.8 \%$ compared to the control (Figure 4 ).

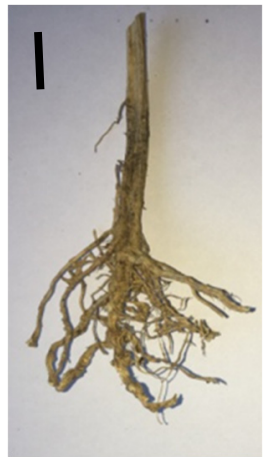

(A)

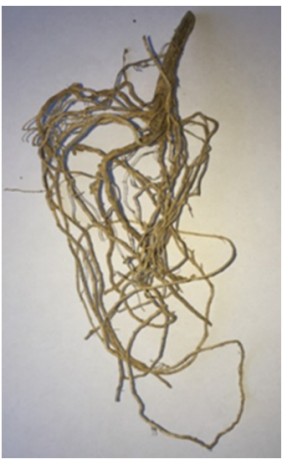

(B)

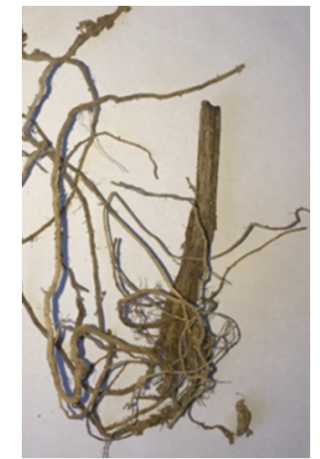

(C)

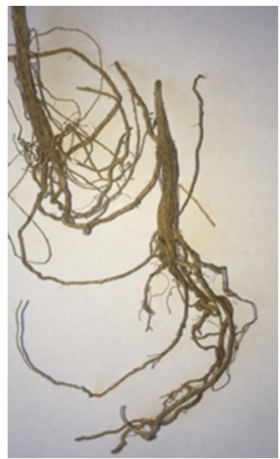

(D)

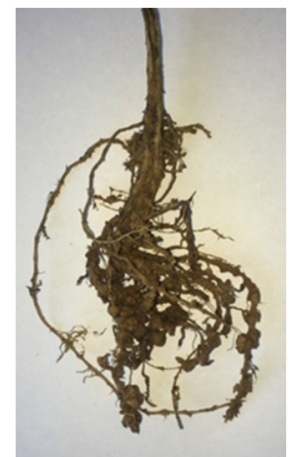

(E)

Figure 5. Effect of B. velezensis BZR 86 and B. velezensis BZR 277 strains on the degree of gall formation on the roots of cucumber plants: (A) B. velezensis BZR86, single treatment; (B) B. velezensis BZR86, double treatment; (C) B. velezensis BZR277, single treatment; (D) B. velezensis BZR277, double treatment; (E) control. Black scale bars represent $1 \mathrm{~cm}$.

In 2018, a double treatment of cucumber plants with the B. velezensis BZR 86 and B. velezensis BZR 277 strains also turned out to be more effective than a single treatment. This may indirectly indicate the ability of the studied strains to enhance the induced systemic resistance of plants. The maximum biometric parameters were recorded for plants treated with the B. velezensis BZR 277 strain. It also showed greater activity against $M$. incognita when it was applied to the root system; two times fewer galls were noted compared to the strain B velezensis BZR 86. As a result, the maximum cucumber yield was recorded with double application of the B. velezensis BZR 277 strain-32.7\% more than in the control, and $12.7 \%$ more than in the option with a double application of the $B$. velezensis BZR 86 strain (Table 1).

\section{Discussion}

In this study, we assessed the disease control efficacy of B. velezensis BZR 86 and B. velezensis BZR 277 strains against the root-knot nematode $M$. incognita of cucumber plants in the greenhouse.

Many researchers note the ability of Bacillus strains bacteria to reduce the number and harmfulness of phytoparasitic nematodes that attack agricultural crops $[3,21]$. One of the mechanisms of the nematicidal action of Bacillus strains is the synthesis of extracellular enzymes [22-25]. It is likely that extracellular enzymes, such as proteases, lipases, and chitinases, are capable of destroying the physical and physiological integrity of the nematode cuticle and eggs [26]. It was shown that enzymes can damage the egg membrane of nematodes, which consists of a protein matrix and a chitinous layer [27]. In addition, chitin is the main component of the nematode pharynx. Therefore, any disturbance in the synthesis or hydrolysis of chitin can lead to the death of nematode embryos, the laying of defective eggs, or a violation of molting [28]. The enzymatic activity (chitinase and protease) of the $B$. megaterium culture supernatant provided a nematicidal effect in the range of 21-30\% against the larvae of Meloidogyne sp. and 30-37\% against its eggs [29]. 
Some studies revealed the ability of Bacillus firmus to synthesize toxins that reduced the number of eggs of Meloidogyne spp. [30]. It is known that effective lysis of the cell walls of pests is associated with the complex action of various hydrolytic enzymes. Geng et al. [31] found the ability of $B$. firmus to produce peptidase group enzymes capable of destroying intestinal tissue of nematodes. That research served as the basis for the development of biological products Nortica and VOTiVO, which were successfully used in the United States. Other studies revealed 100\% mortality of the second age larvae of the root-knot nematodes $M$. incognita and $M$. javanica within $72 \mathrm{~h}$ caused by liquid cultures based on $B$. thuringiensis and P. fluorescens bacterial strains. Furthermore, these bacteria stimulated plant growth [32].

Our results demonstrated the activity of Bacillus strains against $M$. incognita on cucumber plants (up to $76.4 \%$ ). According to the study, we assumed the ability of Bacillus strains to synthesize proteolytic enzymes that caused the death of nematodes [10]. In Iran, the treatment of tomato plants with the filtrate of the bacterial culture Bacillus sp. in vitro caused mortality of $M$. incognita juveniles by $72 \%$ [33]. The use of chitinase and protease synthesized by the $B$. pumilus L1 strain in vitro reduced the hatching of $M$. arenaria eggs by $78 \%$, and the mortality of juveniles was $98.6 \%$ compared to the control. In this study, structural damage of nematode bodies and eggs was noted [34]. Under in vitro conditions, B. subtilis culture filtrates inhibited the hatching of M. incognita eggs by $94.6 \%$ and caused mortality of juveniles by $91.3 \%$ [35]. Laboratory studies of B. subtilis strains exhibiting nematicidal activity against $M$. incognita showed that the use of a cell suspension provided the mortality of juveniles at the level of $39.3 \%$, while the mortality rate when using the supernatant was $82.3-90.7 \%$, which may be caused by the ability of $B$. subtilis to produce lytic enzymes [36]. These data are confirmed by the studies carried out in 2020, during which liquid culture filtrate caused the death of $90 \%$ of juveniles of the second stage and reduced egg hatchability by $97 \%$ in vitro [37].

Our studies confirmed the ability of B. velezensis BZR 86 and B. velezensis BZR 277 to produce a number of enzymes. The $B$. velezensis BZR 86 strain discovered chitinolytic activity. As to the B. velezensis BZR 277 strain, a high level of synthesis of lipases and proteases was noted, which may be partially involved in the process of suppression of the nematode $M$. incognita. Various factors have a significant effect on the growth of the number of cells and the synthesis of enzymes: temperature, acidity, the composition of the nutrient medium, and the incubation period [38]. Therefore, it is important to optimize the cultivation conditions for improving the nematicidal activity of bacterial strains. For example, Cheba et al. [39] showed that incubation of the Bacillus sp. R2 at $30^{\circ} \mathrm{C}$ led to the highest level of chitinase synthesis. B. cereus JK-XZ3 filtrate cultivated at $30^{\circ} \mathrm{C}$ showed the highest nematicidal activity, resulting in $100 \%$ mortality of Bursaphelenchus xylophilus [40]. However, Dukariya and Kumar [41] reported maximum chitinase productivity at $37{ }^{\circ} \mathrm{C}$.

In our studies, we improved the cultivation conditions for strains exhibiting nematicidal activity according to a criterion, such as the number of colony-forming units. It is known that Bacillus strains are capable of growing in a temperature range of $5.5^{\circ} \mathrm{C}$ to $55.7^{\circ} \mathrm{C}$ [42-44]. According to the data obtained for the B. velezensis BZR 86 strain, the optimum temperature is $35^{\circ} \mathrm{C}$, and for the B. velezensis BZR 277 strain- $-30^{\circ} \mathrm{C}$. Our study is fully consistent with the conclusions of Park et al. [45], according to whom, when cultivating the B. velezensis GH1-13 strain, a titer of $7.5 \times 10^{9} \mathrm{CFU} / \mathrm{mL}$ was obtained at $37^{\circ} \mathrm{C}$. A similar pattern was noted in the study by Usanov et al. [46], according to which an increase in the cultivation temperature to $40{ }^{\circ} \mathrm{C}$ has a positive effect on the growth dynamics of the B. subtilis, and the number of colony-forming units exceeds the control by $88.9 \%$.

In our study, the maximum titer of both strains was observed at $\mathrm{pH} 3$. However, it should be noted that when the strains were cultivated on media with different levels of acidity, no significant jumps in cell density were observed. These data are confirmed by Mohapatra et al. [47] 2015, according to whom, insignificant fluctuations in CFU were observed during cultivation of the Bacillus sp. P1on media with pH 6-9 (5.0-8.4 × 10 $5 \mathrm{CFU} / \mathrm{mL})$. $B$. velezensis XT1 strain was able to grow in a wide $\mathrm{pH}$ range of 5-10 [48]. A relatively high 
cell density at pH 3 was noted during the cultivation of the B. velezensis CE 100 strain, the initial $\mathrm{pH}$ of the medium of 7.5 decreased to 4.7 over $24 \mathrm{~h}$ of cultivation, which may indicate the ability of some $B$. velezensis strains to grow in an acidic medium [49].

Molasses has been shown to optimize the parameters of growing strains-producers of biological products [50,51]. Being a source of not only sugars, but also vitamins, macroand microelements, this ingredient ensures the active growth of microorganism cultures. For strains B. velezensis BZR 86 and B. velezensis BZR 277, the cell titer in liquid cultures using molasses as media component was 2-3 times higher than on media with sucrose, glucose, and glycerol and amounted up to $(1.6 \pm 0.03) \times 10^{9} \mathrm{CFU} / \mathrm{mL}$ for the $B$. velezensis BZR 86 strain and $(5.8 \pm 0.39) \times 10^{8} \mathrm{CFU} / \mathrm{mL}$ for the B. velezensis BZR 277 strain. Peptone was the most preferred source of nitrogen nutrition for both strains. It should be noted that the B. velezensis BZR 86 strain turned out to be more sensitive to the source of nitrogen nutrition: when $\mathrm{NaNO}_{3}$ was added to the nutrient medium, the titer was $(3.7 \pm 0.4) \times 10^{6} \mathrm{CFU} / \mathrm{mL}$, and when peptone was added- $-(1.8 \pm 0.07) \times 10^{8} \mathrm{CFU} / \mathrm{mL}$. These results are consistent with the studies on the optimization of the nutrient medium for the cultivation of the $B$. velezensis NRC-1 strain, according to which the maximum cell growth and mannanase synthesis were achieved on the medium with peptone [52].

The cultivation time is an important parameter for the growth of biocontrol agents. If bacterial cultures are incubated for too long, some metabolites may be converted to other compounds. In contrast, if the incubation period is not long enough, it is possible that important metabolites have not yet been synthesized (for example, enzymes that are formed during the stationary growth phase). This demonstrates the importance of making bacterial growth curves [53]. During our research, it was noted that the phase of initial growth began after the introduction of a parent culture with a titer of $(1.4 \pm 0.05) \times 10^{8} \mathrm{CFU} / \mathrm{mL}$ in the B. velezensis BZR 277 strain and $(8.1 \pm 0.01) \times 10^{7} \mathrm{CFU} / \mathrm{mL}$ in the $B$. velezensis 86 strain and lasted up to $8 \mathrm{~h}$. The phase of the most active growth began $16 \mathrm{~h}$ after the introduction of the mother culture and began to decay after $36 \mathrm{~h}$ for the B. velezensis 277 strain and from 8 to $36 \mathrm{~h}$ for the $B$. velezensis 86 strain. The maximum cell titer was observed during this period and amounted to $(1.7 \pm 0.02) \times 10^{9} \mathrm{CFU} / \mathrm{mL}$ in the B. velezensis BZR 277 strain and $(1.3 \pm 0.11) \times 10^{9} \mathrm{CFU} / \mathrm{mL}$ in the B. velezensis BZR 86 strain. The phase of bacterial cell death occurred $36 \mathrm{~h}$ after the start of cultivation for both strains, which contradicts the data obtained in the study of the cultivation of the B. velezensis IP22 strain, according to which the stationary phase lasted up to $60 \mathrm{~h}$ [54].

Three-year vegetation tests on the Courage variety of cucumber plants under the greenhouse conditions showed that plants treated with the B. velezensis BZR 86 and $B$. velezensis BZR 277 strains developed more intensively; the growth and development indicators significantly exceeded the control ones. This tendency was observed in research by Sahebani and Omranzade [55], according to which the introduction of a liquid culture based on B. megaterium wr101 into the soil infected with M. javanica contributed to an increase in the mass of cucumber shoots twice as compared to the control. Other authors showed that the decrease in the number of $\mathrm{M}$. incognita contributed to the improvement of plant development, which was manifested by an increase in biometric indicators and in cucumbers compared with the control. It was noted that the use of two Bacillus strains contributed to the formation of an additional cucumber yield from $4.6 \%$ to $45.8 \%$, which confirms the results of the 2019 studies, in which the treatment of cucumber plants with a liquid culture based on the B. subtilis Bs-1 strain provided an additional yield of up to $53.1 \%$ in combination with a high nematicidal effect against $M$. incognita [56].

In our research, we showed that in three consecutive years, application of two Bacillus strains in the greenhouse demonstrated that the number of galls per gram of cucumber root mass decreased by 13 times for the B. velezensis BZR 277 strain, and by 7.2 times for the $B$. velezensis BZR 86 strain. In general, the B. velezensis BZR 277 strain exhibited a more pronounced nematicidal and plant growth-promoting effect. Probably, such difference is due to the selectivity of the nematicidal action of lipases and proteases synthesized by the $B$. velezensis BZR 277 strain against predominantly adult nematodes. It should be 
noted that the cuticle of nematodes contains different types of structural proteins and their proportions change throughout their life cycle as other authors have shown [54,57].

\section{Materials and Methods}

\subsection{Microorganisms}

B. velezensis BZR 86 and B. velezensis BZR 277 were isolated from the field soil of the Krasnodar region $\left(45^{\circ} 1^{\prime} \mathrm{N}, 38^{\circ} 59^{\prime} \mathrm{E}\right)$. Winter wheat plants were selected under aseptic conditions, placed in sterile bags, and stored in a refrigerator at $+4{ }^{\circ} \mathrm{C}$. The strains were isolated from the root zone of winter wheat plants by the method of successive washing of the roots from adjacent soil particles [58]. The roots with soil were placed in a flask with $100 \mathrm{~mL}$ of sterile water and shaken for $40 \mathrm{~min}$ at $180 \mathrm{rpm}$. The roots were removed from the flask with sterile tweezers and transferred to the next flask containing $100 \mathrm{~mL}$ of sterile tap water. The procedure was repeated, successively washing the roots in three flasks (40 min each). The bacteria were inoculated by streaking from the second and third flasks. The B. velezensis BZR 277 strain was inoculated on potato-glucose agar and the $B$. velezensis BZR 86 strain on a medium with chitinase. Petri dishes with B. velezensis BZR 86 strain were incubated at $+28^{\circ} \mathrm{C}$ for three days. Petri dishes with B. velezensis BZR 277 strain were incubated at $+4{ }^{\circ} \mathrm{C}$ for 21 days. Isolated colonies were streaked onto potato-glucose agar. This procedure was repeated until a pure culture of the strain was obtained in the Petri dish.

Strains deposited in the Bioresource collection "State collection of beneficial insects, mites and microorganisms" of the Federal State Budgetary Scientific Institution "Federal Research Center of Biological Plant Protection" (FSBSI “FRCBPP”) (registry number 585858).

\subsection{MALDI-TOF MS Analysis}

MALDI-TOF MS analysis was performed to identify bacterial cultures. The taxonomic status of bacterial cultures was determined by the BactoScreen analyzer. The spectra were analyzed using the BactoScreen-ID software version 2.4. In addition, the BRUKER autoflex III smartbeam and flexcontrol 3.0 software was used. The analysis was carried out using a database containing the spectra of 3995 microorganisms. The values obtained were expressed as a logarithmic score. In particular, a score of 2.0-identification at the species level is allowed, a score in the range of $1.7 \pm 2.0$-identification only at the genus level, a score below 1.7-the absence of significant similarity of the obtained spectrum with any record of the database (not reliable identification). E. coli DH5a proteins were used as a bacterial standard.

\subsection{Molecular Genetic Identification of Strains}

Isolation of genomic DNA preparations of B. velezensis BZR 86 and B. velezensis BZR 277 strains was performed using the DNeasy PowerSoil Kit, QIAGEN (Hilden, Germany) according to standard protocols. The amount of isolated DNA was determined by the fluorometric method using Qubit dsDNA HS Assay Kit, ThermoFisher Scientific (Waltham, MA, USA) according to the manufacturer's protocols.

To determine the complete genomes of B. velezensis BZR 86 and B. velezensis BZR 277 strains, a combined strategy was used, including the use of two high-productive sequencing platforms-Illumina (MiSeq) and monomolecular sequencing on MinIon (Oxford Nanopore). At the first stage, a genomic library of "random fragments" was prepared, suitable for sequencing on the MiSeq device (Illumina) using the NEBNext ultra II DNA Library kit (NEB) and then read on the MiSeq genomic analyzer. At the second stage, the genome was additionally sequenced using monomolecular nanopore sequencing technology (MinION instrument from Oxford Nanopore). To prepare genomic libraries suitable for sequencing on the MinION device, a Ligation Sequencing kit 1D (Oxford Nanopore) was used according to the manufacturer's recommendations. Sequencing on the MinION was performed using the Ligation Sequencing kit 1D protocol using FLO-MIN110 wells. The sequencing results were saved in a FAST5 file. Using the flash program [59], paired intersecting reads obtained on MiSeq (Illumina) were combined and the poor-quality 
ends of the reads were cut using the Sickle program. Structural (protein-coding) genes and ribosomal RNA genes were identified and their functions were theoretically predicted using the RAST server [60].

Multiple alignments of the concatenated amino acid sequences of 120 bacterial singlecopy marker genes were performed using the Genome Taxonomy Data Base (GTDB-Tk v. 1.3.0 toolkit software) from RefSeq and Genbank genomes (USA) [61]. This multiple alignment was used to construct a maximum similar phylogenetic tree using PhyML v.3.3 with default parameters [62]. Internal branching support was assessed using a Bayesian test in PhyML.

The obtained B. velezensis BZR 86 sequences were deposited in the NCBI database under accession numbers PRJNA677970 (BioProject), SRX9502286 (SRA), and SAMN16784691 (BioSample). The obtained B. velezensis BZR 277 sequences were deposited into the NCBI database under accession numbers PRJNA588983 (BioProject), SRX9502288 (SRA), and SAMN16784690 (BioSample).

\subsection{Cultural and Morphological Characteristics of Bacillus strains}

Cultural and morphological characteristics of the strains were studied on meatpeptone agar (MPA) and potato-glucose agar (PGA) using an Axio Scope A1 microscope (Jena, Germany). The shape and size of the cells, the ability to form spores, the location of spores in the cells, the ability to move, and coloring were determined according to Gram. We studied the growth characteristics, shape, size, surface, profile, color, shine, and transparency of the colonies, as well as their edge, structure, and consistency [63].

\subsection{Enzymatic Activity of Bacillus strains}

The enzymatic activity of antagonistic bacterial strains was carried out using generally accepted methods [64]. Chitinase, lipase, and protease activity was determined. To determine the chitinolytic activity, a synthetic medium of the following composition was used, g/l: sucrose-20.0; $\mathrm{NaNO}_{3}-3.0 ; \mathrm{KH}_{2} \mathrm{PO}_{4}-1.0 ; \mathrm{MgSO} 4-0.3$; chalk-10.0; and agar-20.0. The medium was sterilized by autoclaving, poured into Petri dishes, and cooled. Inoculating of bacterial strains was performed by streaking. Petri dishes were incubated for $7-10$ days at a temperature of $+28.0^{\circ} \mathrm{C}$. Chitinase activity was judged by the formation of clearing zones around the colonies.

Lipolytic activity was determined on yolk agar of the following composition, g/l: peptone-40.0; glucose-2.0; $\mathrm{Na}_{2} \mathrm{HPO}_{4}-5.0 ; \mathrm{NaCl}-2.0 ; \mathrm{MgSO}_{4} 0.5 \%$ solution-2.0 mL; and agar-25.0. 4. The medium was sterilized by autoclaving and cooled to $+60.0{ }^{\circ} \mathrm{C}$. The egg shell was disinfected with alcohol and allowed to dry. The egg was broken and the yolk was separated from the egg white. The yolk, in compliance with the rules of asepsis, was transferred into molten agar and stirred until a homogeneous suspension was obtained, which was poured into Petri dishes and left to solidify. Inoculating of bacterial strains was performed by streaking. Petri dishes were incubated for 14 days at a temperature of $+28.0^{\circ} \mathrm{C}$. Then the lid of the Petri dish was removed and the surface was carefully examined under oblique illumination. Lipolytic activity was judged by the formation of an oily, glistening, or nacreous layer above and around the bacterial colony on the agar surface.

To determine protease activity, sterile (autoclaved) skim milk was mixed at $+50.0^{\circ} \mathrm{C}$ with an equal volume of $4 \%$ molten aqueous agar. Inoculating of bacterial strains was performed by streaking. Petri dishes were incubated for 14 days. Protease activity was judged by the formation of clearing zones around the colonies.

Gelatinase activity was tested on meat-peptone gelatin, g/l: meat-peptone broth-39.0; and gelatin-150.0. The medium was poured into test tubes, sterilized by autoclaving, and cooled at room temperature. Inoculating of bacterial strains was carried out by injection. The tubes were incubated for 7-10 days at room temperature. The liquefaction of the gelatin was observed visually. The intensity and form of liquefaction were indicated. 


\subsection{Optimal Conditions for the Cultivation of Bacillus strains}

To determine the optimal cultivation temperature, the strains were incubated at 20.0, 25.0, 30.0, and $35.0^{\circ} \mathrm{C}$. Czapek medium for bacteria was used as a basis [63]. Carbon sources sucrose, glucose, molasses, and glycerol were added in the test media. In the study of carbon sources nitrogen sodium nitrate served as the unchanged nutrition component. In determining the optimal sources of nitrogen nutrition peptone, $\mathrm{NaNO}_{3}$, yeast and corn extracts were tested with glucose as the only (constant) carbon source. To choose the optimal acidity of the medium, the strains were grown on a liquid medium, $\mathrm{g} / \mathrm{L}$ $\mathrm{KCl}-0.5, \mathrm{MgSO}_{4} \times 7 \mathrm{H}_{2} \mathrm{O}-0.5, \mathrm{~K}_{2} \mathrm{HPO}_{4} \times 3 \mathrm{H}_{2} \mathrm{O}-1.0, \mathrm{CaCO}_{3}-3.0, \mathrm{FeSO}_{4} \times 7 \mathrm{H} 2 \mathrm{O}-0.01$ corn extract-2.0, molasses-20.0 at optimum temperatures. By adding lactic acid or alkali (4N NaOH solution), the medium $\mathrm{pH}$ was adjusted to 3.0, 6.0, 8.0, and 10.0 using a Sartorius PB-11 pH-meter (Goettingen, Germany). To determine the optimal cultivation time, samples for analysis were taken after 8, 16, 24, 36, 48, and $72 \mathrm{~h}$ from the start of cultivation. All experiments were replicated three times. For all experiments, a liquid culture was obtained by the method of periodic cultivation. Incubation was carried out in thermostat cell cultivation systems (180 rpm) "New Brunswick Scientific Excella E25" (Enfield, CT, USA) for $48 \mathrm{~h}$. Periodic cultivation was carried out in conical flasks ( $350 \mathrm{~mL}$ ) with a nutrient medium volume of $100 \mathrm{~mL}$ and preliminary introduction of stock culture ( $2 \%$ of the nutrient medium volume). The stock culture was obtained by introducing agar blocks with the studied strains into conical flasks and subsequent cultivation.

At the end of cultivation, the number of bacterial cells was determined by the Koch method in all experiments on MPA [63]. The grown colonies were counted with the Color Qcount, Spiral Biotech, 530 (Canton, MA, USA) system for the automatic counting colonies.

In our research we used Unique Scientific Facility "New generation technological line for developing microbiological plant protection products" of Federal Research Center of Biological Plant Protection, Krasnodar, Russia (http:/ / ckp-rf.ru/\%E2\%84\%96671367, accessed on 21 August 2019).

\subsection{Greenhouse Evaluation of Bacillus strains}

A liquid culture of bacterial strains was obtained in New Brunswick Scientific Excella E25 cell culture systems (180 rpm) on a potato-glucose medium, g/L: potato broth-500.0 and glucose-20.0. Cultivation was carried out for $48 \mathrm{~h}$.

The average temperature in the greenhouse was $27.5^{\circ} \mathrm{C}$ in May, $35.4{ }^{\circ} \mathrm{C}$ in June, $35.6{ }^{\circ} \mathrm{C}$ in July, and $37.5^{\circ} \mathrm{C}$ in August.

The tests were carried out in conditions of protected ground in a greenhouse with a total area of $100 \mathrm{~m}^{2}$. Five variants of the experiment were randomized in three times repetition and the area of each plot was $5 \mathrm{~m}^{2}$. There were eight sample plants in each plot. The cucumber plants of Courage variety with natural infection by root-knot nematode were used. The number of galls was determined by the Guskova method [65]. The starting titer of the liquid culture preparation was $1 \times 10^{9} \mathrm{CFU} / \mathrm{mL}$. The application rate of the preparation was $360 \mathrm{~L} / \mathrm{ha}(50-60 \mathrm{~mL}$ per plant). The liquid culture was diluted at the rate of $60 \mathrm{~mL}$ per liter of water. The consumption rate of the working fluid is up to $6000 \mathrm{~L} / \mathrm{ha}$. In total, $200 \mathrm{~mL}$ of the preparation was added under the root of each cucumber plant.

Assessment of nematicidal activity of the strains was carried to the scheme:

1. Single treatment by suspension of B. velezensis BZR 86 before planting.

2. Double treatment by suspension of B. velezensis BZR 86 during planting followed by treatment under the plant root 3 weeks after planting.

3. Single treatment by suspension of B. velezensis BZR 277 before planting.

4. Double treatment by suspension of B. velezensis BZR 277 during planting followed by treatment under the plant root 3 weeks after planting.

5. Plants without treatment were used as control.

The effectiveness of the bacterial strains was determined by plant height, leaf area, shoot mass and root mass, the ratio of the number of galls to the mass of roots (damage score), and yield. 
The root gall severity was based on gall indices (GI) measured on 0 to 5 scales: $0-\mathrm{GI}=0 \%$; $1-\mathrm{GI}=10$ to $20 \%$; $2-\mathrm{GI}=21$ to $50 \%$; $3-\mathrm{GI}=51$ to $80 \%$; $4-\mathrm{GI}=81$ to $100 \%$, $5-\mathrm{GI}=>100 \%$ on roots $[66]$.

\subsection{Statistical Analysis}

Statistical data processing was performed by standard methods using MS Excel and ANOVA program for Windows. All data were expressed as mean from triplicate samples \pm standard deviation. Duncan test was used, and differences were considered statistically significant at $p<0.05$ level.

\section{Conclusions}

BZR 277 and BZR 86 strains are endophytic bacteria associated with the roots of winter wheat plants from Krasnodar Krai (Russia). They are representatives of $B$. velezensis. They possess the properties of PGPR, exhibiting enzymatic activity and promoting the growth of aboveground and underground parts of the cucumber variety Courage and increasing its yield. In addition, BZR 277 and BZR 86 strains have nematicidal activity against the root-knot nematode $M$. incognita. However, further research is needed on the mechanisms associated with the growth-stimulating and biocontrol activity of the strains.

Author Contributions: Project administration, A.M.A. and V.D.N.; writing-original draft preparation, A.I.H.; resources, L.N.B.; investigation, G.A.S., L.V.Y., and N.M.S.; data curation, E.V.K.; software, A.V.G. All authors have read and agreed to the published version of the manuscript.

Funding: The study of bacterial strains, cultivation conditions, and greenhouse evaluation was carried out within the framework of the State Assignment of the Ministry of Science and Higher Education of the Russian Federation, No. FGRN-2022-0005. DNA sequencing of the strain BZR 277, BZR 86, and the construction of the phylogenetic tree based on the whole genome sequencing was supported by a project of the Kuban Science Foundation (grant MFI-20.1/68).

Institutional Review Board Statement: Not applicable.

Informed Consent Statement: Not applicable.

Data Availability Statement: Data is contained within the article.

Conflicts of Interest: The authors declare no conflict of interest.

\section{References}

1. Jones, J.T.; Haegeman, A.; Danchin, E.G.; Gaur, H.S.; Helder, J.; Jones, M.G.; Kikuchi, T.; Manzanilla-López, R.; Palomares-Rius, J.E.; Wesemael, W.M.L.; et al. Top 10 plant-parasitic nematodes in molecular plant pathology. Mol. Plant Pathol. 2013, 14, 946-961. [CrossRef]

2. Aydinli, G.; Mennan, S. Identification of root-knot nematodes (Meloidogyne spp.) from greenhouses in the Middle Black Sea Region of Turkey. Turk. J. Zool. 2016, 40, 675-685. [CrossRef]

3. Briar, S.S.; Wichman, D.; Reddy, G.V. Plant-parasitic nematode problems in organic agriculture. In Organic Farming for Sustainable Agriculture. Sustainable Development and Biodiversity; Nandwani, D., Ed.; Springer: Cham, Switzerland, 2016; Volume 9, pp. 107-122. [CrossRef]

4. Topalović, O.; Bredenbruch, S.; Schleker, A.S.S.; Heuer, H. Microbes attaching to endoparasitic phytonematodes in soil trigger plant defense upon root penetration by the nematode. Front. Plant Sci. 2020, 11, 138. [CrossRef] [PubMed]

5. Tagiev, M.M. Gall nematodes (Meloidogyne) on the Apsheron Peninsula and their control. Succes. Mod. Sci. Educ. 2015, 5, 22-24.

6. Singh, M.C.; Yousuf, A.; Singh, J.P. Greenhouse microclimate modeling under cropped conditions: A review. Res. Environ. Life Sci. 2016, 9, 1552-1557.

7. Abd-Elgawad, M.M.M. Optimizing safe approaches to manage plant-parasitic nematodes. Plants 2021, 10, 1911. [CrossRef]

8. Peng, D.; Lin, J.; Huang, Q.; Zheng, W.; Liu, G.; Zheng, J.; Zhu, L.; Sun, M. A novel metalloproteinase virulence factor is involved in Bacillus thuringiensis pathogenesis in nematodes and insects. Environ. Microbiol. 2016, 18, 846-862. [CrossRef] [PubMed]

9. Zheng, Z.; Zheng, J.; Zhang, Z.; Peng, D.; Sun, M. Nematicidal spore-forming Bacilli share similar virulence factors and mechanisms. Sci. Rep. 2016, 6, 31341. [CrossRef]

10. Aballay, E.; Ordenes, P.; Mårtensson, A.M.; Persson, P. Effects of rhizobacteria on parasitism by Meloidogyne ethiopica on grapevines. Eur. J. Plant Pathol. 2012, 135, 137-145. [CrossRef]

11. Ann, Y.C. Screening for Nematicidal activities of Bacillus species against root knot nematode (Meloidogyne incognita). Am. J. Exp. Agric. 2013, 3, 794-805. [CrossRef] 
12. Mahesha, H.S.; Ravichandra, N.G.; Rao, M.S.; Narasegowda, N.C.; Shreeshail, S.; Shivalingappa, H. Bio-efficacy of different strains of Bacillus spp. against Meloidogyne incognita under in vitro. Int. J. Curr. Microbiol. Appl. Sci. 2017, 6, 2511-2517. [CrossRef]

13. Abdel-Salam, M.S.; Ameen, H.H.; Soliman, G.M.; Elkelany, U.S.; Asar, A.M. Improving the nematicidal potential of Bacillus velezensis and Lysinibacillus sphaericus against the root-knot nematode Meloidogyne incognita using protoplast fusion technique. Egypt. J. Biol. Pest Control 2018, 28, 31. [CrossRef]

14. Jang, J.Y.; Choi, Y.H.; Shin, T.S.; Kim, T.H.; Shin, K.-S.; Park, H.W.; Kim, Y.H.; Kim, H.; Choi, G.J.; Jang, K.S.; et al. Biological control of Meloidogyne incognita by Aspergillus niger F22 producing oxalic acid. PLoS ONE 2016, 11, e0156230. [CrossRef]

15. Nguyen, V.T.; Yu, N.H.; Lee, Y.; Hwang, I.M.; Bui, H.X.; Kim, J.-C. Nematicidal activity of cyclopiazonic acid derived from Penicillium commune against root-knot nematodes and optimization of the culture fermentation process. Front. Microbiol. 2021, 12, 726504. [CrossRef] [PubMed]

16. Kim, Y.J.; Duraisamy, K.; Jeong, M.-H.; Park, S.-Y.; Kim, S.; Lee, Y.; Nguyen, V.T.; Yu, N.H.; Park, A.R.; Kim, J.-C. Nematicidal activity of chemical intermediates of grammicin biosynthesis pathway in Xylaria grammica EL000614 against Meloidogyne incognita. Molecules 2021, 26, 4675. [CrossRef]

17. Stoytcheva, M. Pesticides in the Modern World_Pesticides Use and Management; InTech: London, UK, 2011; 532p.

18. The State Catalog of pesticides and agrochemicals approved for use on the territory of the Russian Federation. Ministry of Agriculture: Moscow, Russia, 2021; pp. 143-144.

19. Asaturova, A.M.; Dubyaga, V.M.; Tomashevich, N.S.; Zharnikova, M.D. Selection of promising biological control agents to protect winter wheat against Fusarium pathogens. Electron. Polythem. Sci. J. KubSAU 2012, 75. Available online: http:/ / ej.kubagro.ru/2012/01/pdf/37.pdf (accessed on 18 November 2021).

20. Lychagina, S.V.; Migunova, V.D.; Asaturova, A.M. The influence of Bacillus bacteria on the development of cucumber plants affected by the gall nematode. Theor. Pract. Control. Parasit. Dis. 2017, 18, 227-229.

21. Abd El-Rahman, A.F.; Shaheen, H.A.; Abd El-Aziz, R.M.; Ibrahim, D.S.S. Influence of hydrogen cyanide-producing rhizobacteria in controlling the crown gall and root-knot nematode, Meloidogyne incognita. Egypt. J. Biol. Pest Control 2019, 29, 41. [CrossRef]

22. Chahal, P.P.K.; Chahal, V.P.S. Effect of thuricide on the hatching of eggs root-knot nematode, Meloidogyne incognita. Curr. Nematol. 1993, 4, 247.

23. Dhawan, S.C.; Sarvjeet, K.; Aqbal, S. Effect of Bacillus thuringiensis on the mortality of root-knot nematode, Meloidogyne incognita. Indian J. Nematol. 2004, 34, 98-99.

24. Vijayalakshmi, S.; Ranjitha, J.; Rajeswari, V.D. Enzyme production ability by Bacillus subtilis and Bacillus licheniformisA comparative study. Asian J. Pharm. Clin. Res. 2013, 6, 29-32.

25. Mota, M.S.; Gomes, C.B.; Souza Júnior, I.T.; Moura, A.B. Bacterial selection for biological control of plant disease: Criterion determination and validation. Brazil. J. Microbiol. 2017, 48, 62-70. [CrossRef]

26. Dihingia, S.; Das, D.; Bora, S. Effect of microbial secretion on inhibitory effect of phytonematode: A review. Int. J. Inform. Res. Rev. 2017, 04, 4275-4280.

27. Li, X.; Hu, H.J.; Li, J.Y.; Wang, C.; Chen, S.L.; Yan, S.Z. Effects of the endophytic bacteria Bacillus cereus BCM2 on tomato root exudates and Meloidogyne incognita infection. Plant Dis. 2019, 103, 1551-1558. [CrossRef]

28. Chen, Q.; Peng, D. Nematode Chitin and Application. Adv. Exp. Med. Biol. 2019, 1142, $209-219$.

29. Tran, T.P.H.; Wang, S.-L.; Nguyen, V.B.; Tran, D.M.; Nguyen, D.S.; Nguyen, A.D. Study of novel endophytic bacteria for biocontrol of black pepper root-knot nematodes in the central highlands of Vietnam. Agronomy 2019, 9, 714. [CrossRef]

30. Mendoza, A.R.; Kiewnick, S.; Sikora, R.A. In vitro activity of Bacillus firmus against the burrowing nematode Radopholus similis the root-knot nematode Meloidogyne incognita and the stem nematode Ditylenchus dipsaci. Biocontrol Sci. Technol. 2008, 18, 377-389. [CrossRef]

31. Geng, C.; Nie, X.; Tang, Z.; Zhang, Y.; Lin, J.; Sun, M.; Peng, D. A novel serine protease, Sep1, from Bacillus firmus DS-1 has nematicidal activity and degrades multiple intestinal-associated nematode proteins. Sci. Rep. 2016, 6, 25012. [CrossRef]

32. Mekete, T.J.; Kiewnick, S.; Sikora, R. Endophytic bacteria from Ethiopian coffee plants and their potential to antagonize Meloidogyne incognita. Nematology 2009, 11, 117-127. [CrossRef]

33. Ramezani, M.M.; Mahdikhani, M.E.; Baghaee, R.S. The nematicidal potential of local Bacillus species against the root-knot nematode infecting greenhouse tomatoes. Biocontrol Sci. Technol. 2014, 24, 279-290. [CrossRef]

34. Lee, Y.S.; Kim, K.Y. Antagonistic potential of Bacillus pumilus L1 against root-knot nematode, Meloidogyne arenaria. J. Phytopathol. 2016, 164, 29-39. [CrossRef]

35. Rao, M.S.; Kamalnath, M.; Umamaheswari, R.; Rajinikanth, R.; Prabu, P.; Priti, K.; Grace, G.N.; Chaya, M.K.; Gopalakrishnan, C. Bacillus subtilis IIHR BS-2 enriched vermicompost controls root knot nematode and soft rot disease complex in carrot. Sci. Hortic. 2017, 218, 56-62. [CrossRef]

36. Basyony, A.G.; Abo-Zaid, G.A. Biocontrol of the root-knot nematode, Meloidogyne incognita, using an eco-friendly formulation from Bacillus subtilis, lab and greenhouse studies. Egypt. J. Biol. Pest Control 2018, 28, 87. [CrossRef]

37. Hussain, T.; Haris, M.; Shakeel, A.; Ahmad, G.; Khan, A.A.; Khan, M.A. Bio-nematicidal activities by culture filtrate of Bacillus subtilis HussainT-AMU: New promising biosurfactant bioagent for the management of Root Galling caused by Meloidogyne incognita. Vegetos 2020, 33, 229-238. [CrossRef]

38. Tyc, O.; Song, C.; Dickschat, J.S.; Vos, M.; Garbeva, P. The ecological role of volatile and soluble secondary metabolites produced by soil bacteria. Trends Microbiol. 2017, 25, 280-292. [CrossRef] [PubMed] 
39. Cheba, B.A.; Zaghloul, T.I.; El-Mahdy, A.R.; El-Massry, M.H. Effect of nitrogen sources and fermentation conditions on Bacillus sp. R2 chitinase production. Procedia Manuf. 2018, 22, 280-287. [CrossRef]

40. Zhang, W.J.; Wu, X.Q.; Wang, Y.H. Nematicidal activity of bacteria against Bursaphelenchus xylophilus and its fermentation and culture characteristics. J. Biotechnol. Bull. 2019, 35, 76-82.

41. Dukariya, G.; Kumar, A. Chitinase production from locally isolated Bacillus cereus GS02 from chitinous waste enriched soil. J. Adv. Biol. Biotechnol. 2020, 23, 39-48. [CrossRef]

42. Khadka, S.; Adhikari, S.; Thapa, A.; Panday, R.; Adhikari, M.; Sapkota, S.; Regmi, R.S.; Adhikari, N.P.; Proshad, R.; Koirala, N Screening and optimization of newly isolated thermotolerant Lysinibacillus fusiformis strain SK for protease and antifungal activity. Curr. Microbiol. 2020, 77, 1558-1568. [CrossRef] [PubMed]

43. Gauvry, E.; Mathot, A.G.; Couvert, O.; Leguérinel, I.; Coroller, L. Effects of temperature, pH and water activity on the growth and the sporulation abilities of Bacillus subtilis BSB1. Int. J. Food Microbiol. 2020, 337, 108915. [CrossRef] [PubMed]

44. Pant, G.; Prakash, A.; Pavani, J.V.P.; Bera, S.; Deviram, G.V.N.S.; Kumar, A.; Panchpuri, M.; Prasuna, R.G. Production, optimization and partial purification of protease from Bacillus subtilis. J. Taibah Univ. Sci. 2015, 9, 50-55. [CrossRef]

45. Park, J.-K.; Kim, J.; Lee, C.-W.; Song, J.; Seo, S.-I.; Bong, K.-M.; Kim, D.-H.; Kim, P.I. Mass cultivation and characterization of multifunctional Bacillus velezensis GH1-13. Korean J. Org. Agric. 2019, 27, 65-76. [CrossRef]

46. Usanov, V.S.; Penzin, A.A.; Shishkin, V.V.; Tatarenko, I.Y. Influence of cultivation temperature and active acidity of soybean-corn substrate on the growth dynamics of the Bacillus subtilis bacterium. Far East. Agrar. Bull. 2020, 3, 117-124. [CrossRef]

47. Mohapatra, S.; Samantaray, D.P.; Samantaray, S.M. Study on polyhydroxyalkanoates production using rhizospheric soil bacterial isolates of sweet potato. Ind. J. Sci. Technol. 2015, 8 (Suppl. 7), 57-62. [CrossRef]

48. Torres, M.; Llamas, I.; Torres, B.; Toral, L.; Sampedro, I.; Béjar, V. Growth promotion on horticultural crops and antifungal activity of Bacillus velezensis XT1. App. Soil Ecol. 2020, 150, 103453. [CrossRef]

49. Lee, D.R.; Maung, C.E.H.; Choi, T.G.; Kim, K.Y. Large scale cultivation of Bacillus velezensis CE 100 and effect of its culture on control of Citrus Melanose caused by Diaporthe citri. Korean J. Soil Sci. Fertil. 2021, 54, 297-310.

50. Garcha, S.; Kansal, R.; Gosal, S.K. Molasses growth medium for production of Rhizobium sp. based biofertilizer. Ind. J. Biochem. Biophys. 2019, 56, 378-383.

51. Gojgic-Cvijovic, G.D.; Jakovljevic, D.M.; Loncarevic, B.D.; Todorovic, N.M.; Pergal, M.V.; Ciric, J.; Loosc, K.; Beskoski, V.P.; Vrvic, M.M. Production of levan by Bacillus licheniformis NS032 in sugar beet molasses-based medium. Int. J. Biol. Macromol. 2019, 121, 142-151. [CrossRef]

52. Mazeed, T. Optimization of nutrient composition medium and culture condition for mannanase production by Bacillus velezensis nrc-1 using Taguchi method. Al-Azhar J. Pharm. Sci. 2012, 45, 198-207. [CrossRef]

53. Horak, I.; Engelbrecht, G.; van Rensburg, P.J.J.; Claassens, S. Microbial metabolomics: Essential definitions and the importance of cultivation conditions for utilizing Bacillus species as bionematicides. J. App. Microbiol. 2019, 127, 326-343. [CrossRef]

54. Pajčin, I.; Vlajkov, V.; Frohme, M.; Grebinyk, S.; Grahovac, M.; Mojićević, M.; Grahovac, J. Pepper Bacterial Spot Control by Bacillus velezensis. Bioproc. Solut. Microorg. 2020, 8, 1463. [CrossRef]

55. Sahebani, N.; Omranzade, F. Assessment of plant defence induction and biocontrol potential of Bacillus megaterium wr101 against Meloidogyne javanica. Nematology 2020, 22, 1091-1099. [CrossRef]

56. Cao, H.; Jiao, Y.; Yin, N.; Li, Y.; Ling, J.; Mao, Z.; Yang, Y.; Xie, B. Analysis of the activity and biological control efficacy of the Bacillus subtilis strain Bs-1 against Meloidogyne incognita. Crop Protect. 2019, 122, 125-135. [CrossRef]

57. Castaneda-Alvarez, C.; Aballay, E. Rhizobacteria with nematicide aptitude: Enzymes and compounds associated. World J. Microbiol. Biotechnol. 2016, 32, 203. [CrossRef] [PubMed]

58. Marfenina, O.E. Anthropogenic Ecology of Soil Fungi; Medicine for Everyone: Moscow, Russia, 2005; 196p.

59. Magoc, T.; Salzberg, S. FLASH: Fast length adjustment of short reads to improve genome assemblies. Bioinformatics 2011, 27, 2957-2963. [CrossRef] [PubMed]

60. Aziz, R.K.; Bartels, D.; Best, A.A.; DeJongh, M.; Disz, T.; Edwards, R.A.; Formsma, K.; Gerdes, S.; Glass, E.M.; Kubal, M.; et al. The RAST Server: Rapid annotations using subsystems technology. BMC Genom. 2008, 9, 75. [CrossRef]

61. Chaumeil, P.A.; Mussig, A.J.; Hugenholtz, P.; Parks, D.H. GTDB-Tk: A toolkit to classify genomes with the genome taxonomy database. Bioinformatics 2020, 36, 1925-1927. [CrossRef]

62. Guindon, S.; Dufayard, J.F.; Lefort, V.; Anisimova, M.; Hordijk, W.; Gascuel, O.; Notes, A. New algorithms and methods to estimate maximum-likelihood phylogenies: Assessing the performance of PhyML 3.0. Syst. Biol. 2010, 59, 307-321. [CrossRef] [PubMed]

63. Netrusov, F.I. Workshop on Microbiology; Publishing Center Academy: Moscow, Russia, 2005; pp. $105-107$.

64. Lysak, L.V.; Dobrovol'skaya, D.G.; Skvortsova, I.N. Methods for Assessing Soil Bacterial Diversity and Identifying Soil Bacteria; Max Press: Moscow, Russia, 2003; pp. 56-58.

65. Guskova, L.A.; Metlitskiy, O.Z.; Danilov, L.G. Guidelines for Conducting State Tests of Nematicides; VNIESKH: Moscow, Russia, 1983; 35p.

66. Barker, K.R. An advanced treatise on Meloidogyne. In Methodology; North Carolina State University: Raleigh, NC, USA, 1985; Volume II, pp. 19-35. 